Cite as: "Ward, L. M., Vandenbosch, L., \& Eggermont, S. (In press). The impact of men's magazines on adolescent boys' objectification and courtship beliefs. Journal of Adolescence. doi: 10.1016/j.adolescence.2014.12.004."

The Impact of Men's Magazines on Adolescent Boys' Objectification and Courtship Beliefs Ward ${ }^{\mathrm{a}}$, L. M., Vandenbosch ${ }^{\mathrm{b}}$, L., \& Eggermont ${ }^{\mathrm{c}}$, S. ${ }^{\mathrm{a}}$ University of Michigan, ${ }^{\mathrm{b}}$ University of Amsterdam, ${ }^{\mathrm{c}} \mathrm{KU}$ Leuven 


\begin{abstract}
Although much attention concerning the potential impact of sexualized media has focused on girls and women, less is known about how this content effects boys' perceptions of women and courtship. Accordingly, the current three-wave panel study investigated whether exposure to sexualizing magazines predicts adolescent boys' $(N=592)$ sexually objectifying notions of women and their beliefs about feminine courtship strategies. The results indicated that when boys consumed sexualizing magazines more often, they expressed more gender-stereotypical beliefs about feminine courtship strategies over time. This association was mediated by boys' objectification of women. The possibility of a reciprocal relation whereby beliefs about courtship strategies predict future consumption of sexualizing magazines was also explored but received no support. Discussion focuses on effects of sexualizing media on boys, and supports future research to build on multidisciplinary knowledge.
\end{abstract}

Keywords: $\quad$ magazines, adolescence, objectification, sexualization, courtship strategies 


\section{The Impact of Men's Magazines on Adolescent Boys' Objectification and Courtship Beliefs}

During adolescence, many heterosexual youth transition from same-sex peer groups to developing friendships, romantic ties, and sexual relationships with the other sex (Shulman, Connolly, \& McIsaac, 2011). Guiding these initial efforts are the sexual scripts acquired from socialization agents, such as parents and peers, whose messages teach youth how to select and court partners, and define which partners and behaviors are ideal and appropriate. One notable feature of these sexual scripts is that they are highly gendered, emphasizing certain behaviors as expected for men and others for women. These gender-specific norms have been labeled "The Heterosexual Script," which defines the courtship strategies, commitment orientations, and sexual goals considered appropriate for each sex (Kim et al., 2007). Men are expected to enact the script by actively pursuing sexual relationships, treating women as sexual objects, and avoiding commitment and emotional attachment. Women enact the script by setting sexual limits, using their looks to attract men, prioritizing emotional connections, and acting sexually passive. Although individuals differ in their acceptance of these norms, they are nonetheless aware that their behavior may be judged according to them, and may act in ways fitting the script to minimize censure (Smiler, 2013; Tolman, 2002).

In addition to acquiring these gendered sexual scripts from their parents and peers, youth in the industrialized world also have access to mainstream media that feature abundant examples. Analyses indicate that references to The Heterosexual Script appear 15.5 times per hour in primetime American television programming (Kim et al., 2007). Most frequent are references framing men as sex driven and women as passive, sexual objects. For example, Ferris, Smith, Greenberg, and Smith (2007) found that depictions of women as sexual objects occurred 5.9 times per hour on reality dating programs, and depictions of men as sex driven appeared 3.6 times per hour. Moreover, this content has been found to shape youths' sexual beliefs, with survey and experimental data linking exposure to sexual content on television to stronger support of themes featured in the Heterosexual Script, such as notions of women as sexual objects (Ferris et al., 2007; Ward, 2002; Zurbriggen \& Morgan, 2006). 


\section{Expanding Analyses to Sexualizing Magazines and Adolescent Boys}

Despite evidence linking television use to greater endorsement of specific components of the Heterosexual Script, questions remain about media contributions here. First, because most research has focused on television, less is known about other media, such as magazines, which are often more sexually explicit than TV (Pardun, L'Engle, \& Brown, 2005), and may therefore be a richer source of sexual scripts. Indeed, in a recent study that investigated contributions of multiple media to young men's sexual cognitions, magazine use emerged as the most influential media contributor (Ward et al., 2011). A second limitation is the homogeneity of the samples, with much of the work testing North American college students, often via predominantly female samples. Few analyses have tested younger adolescents, who may be more open to accepting media models because of their minimal real-world experience (Valkenburg \& Peter, 2013; Ward, 2003). Few have focused on adolescent boys, who often consume sexual media at greater rates than adolescent girls (Bleakley, Hennessy, \& Fishbein, 2011). What can adolescent boys learn about women and courtship from magazines?

Although the Heterosexual Script details several roles for women, analyses indicate that the role most prominently featured in magazines is the role of beautiful, sexual object (Ezzell, 2009; Ricciardelli, Clow, \& White, 2010). Sexually objectifying portrayals of women have been found to be highly prevalent in men's magazines, including general interest (e.g. $G Q$ ) and lad magazines (e.g., Maxim), as well as pornographic magazines (e.g., Playboy). In their analysis of editorial photographs in lad magazines Maxim and Stuff, Krassas, Blauwkamp, and Wesselink (2003) found that the dominant role for women was generic sexual object (80.5\%), with less frequent depictions of women in roles such as professional or mother. Similar rates were reported in Baker's (2005) analysis of four men's magazines (e.g., GQ, Maxim), in which $68 \%$ of women were depicted in the sex object function, and $25 \%$ as spouse/partner. Indeed, scholars have criticized magazines for considering female appearance as the most suitable sexual "instrument" that women can and should use to attract or sexually please a man (Bogaert, Turkovich, \& Hafer, 1993; Ricardielli et al., 2010). 
Similar content pervades erotic or pornographic magazines. Although these magazines feature more nudity than lad magazines, specifically exposure of women's breasts and genitals (Bogaert et al., 1993), analyses suggest that rates of sexualizing content are not necessarily higher in pornographic magazines than in lad magazines. Krassas, Blauwkamp, and Wesselink (2001) analyzed portrayals in Playboy, coding every picture that was not an advertisement, and found that the top function for women was sex object (70.9\%), followed by spouse/partner (23.9\%). These rates are comparable to those reported above for lad magazines. Indeed, many researchers (e.g., Ward et al., 2011) study all categories of male-oriented magazines together, not drawing distinctions. For example, in their analysis of 14 diverse men's magazines (e.g., Maxim, Playboy), Stankiewicz and Rosselli (2008) found that $76 \%$ of advertisements that included women featured them as sexual objects. Together, these data indicate that in men's magazines - both lad and pornographic - the most prominent way that women are featured is as sexual objects, valued only for their beauty and sexiness. Thus, this is a critical component of the Heterosexual Script that readers of men's magazines could learn.

\section{Effects of Men's Magazines on Sexual Objectification and Sexual Beliefs}

Regular exposure to sexually objectifying media content is believed to have significant consequences for media consumers. Objectification Theory (Fredrickson \& Roberts, 1997) argues that the pervasiveness of sexual objectification in society gradually socializes girls and women to view themselves as sexual objects to be evaluated on the basis of appearance and sexual appeal. This self-objectification has been shown to have numerous consequences for women, and is associated with disordered eating, body dissatisfaction, and depressive affect (Moradi \& Huang, 2008). Although much attention has focused on how girls/women develop objectifying notions about themselves, less is known about how boys/men develop objectifying notions about women. Objectification theory expects that exposure to sexually objectifying content socializes women and men to treat women's bodies as sexual objects. Therefore, it can be assumed that boys' exposure to 
media featuring this content would lead them to endorse objectifying perspectives of women, just as it might lead women to self-objectify. Indeed, Brooks (1997) describes how regular exposure to sexualizing media may trigger a "centerfold syndrome" among men. This syndrome encompasses a set of stereotypical beliefs about men's and women's sexual roles that assert that gazing at attractive women is natural for men and expected by women; that reduces women to sexual objects; that constructs attractive women as trophies that can be used to gain status; and that privileges nonrelational and recreational sex. According to these two theories, then, it is expected that higher levels of exposure to media content that sexually objectifies women would lead boys/men to internalize and support these perspectives.

Emerging evidence indicates that exposure to sexual content across diverse media does affect young men's beliefs about women and courtship. First, as noted earlier, greater exposure to sexualizing content is associated with men's being more accepting of the notion that women are sexual objects (e.g., Hust \& Lei, 2008; Ward, 2002). For example, Kistler and Lee (2010) found that men exposed to five highly sexual music videos offered more support of objectification of women and traditional gender roles than men without this exposure. Similarly, men who frequently consume sexually explicit media are more likely to spontaneously describe women in sexualized ways than are less frequent consumers (Frable, Johnson, \& Kellman, 1997). Second, evidence indicates that exposure to objectifying media affects men's views about dating partners, leading boys to attribute more importance to slimness/attractiveness in selecting a date (Hargreaves \& Tiggemann, 2003), and increasing the extent to which young men objectify their partners (Zurbriggen, Ramsey, \& Jaworski, 2011). Moreover, after being exposed to centerfold erotica or to TV beauties (e.g., Charlie's Angels), undergraduate men rated both average women and their own spouse as less sexually attractive (Kenrick \& Gutierres, 1980; Kenrick, Gutierres, \& Goldberg, 1989). Together, these findings suggest that this exposure normalizes the sexualization of women for men and generates unattainable expectations of "normal" women (Tolman, 2013). 


\section{The Current Study}

One source teaching boys about girls, sex, and courtship are the mainstream media, especially magazines. The messages conveyed are often highly gendered and frequently follow a Heterosexual script (Kim et al., 2007) in which women are passive, sexual objects who are expected to use their bodies to attract men. To examine the impact of this content, we conducted a three-wave panel study testing whether exposure to sexualizing media predicts boys' sexually objectifying notions of women and their beliefs about courtship. We chose to examine these relations among adolescent boys because we anticipated that exposure to media scripts would impact adolescents' sexuality more strongly than adults', as teen boys have less experience with intimate romantic relationships (Sanchez et al., 2012), and may find interacting with girls puzzling (Smiler, 2013). Also, media use peaks in adolescence (Rideout, Foehr, \& Roberts, 2010), especially for years 11-14. We focus on magazines for they have been shown to be especially high in sexualizing content.

Our choice to conduct a multiple-wave, longitudinal study allowed us many affordances. First, to improve our understanding of causality, we investigated the possibility of a reciprocal relation between sexualizing magazines and boys' sexual beliefs, acknowledging that media content may affect consumers, but also that media consumers select content based on their existing beliefs and values (Festinger, 1957; Zillman \& Bryant, 1985). Although most research examining media use and sexual beliefs is cross-sectional, prior studies indicate that relations go in both directions, and that the process is likely circular (Aubrey, 2007; Bleakly, Hennessy, Fishbein, \& Jordan 2008). We therefore chose to examine both pathways. Second, this methodological approach allowed us to examine the objectification of women as an explanatory mechanism. The notion that women are sexual objects is a prominent feature both of media content and of the male and female aspects of the Heterosexual Script. Scholars have theorized that sexualizing media content increases media users' tendencies to objectify women, and in turn objectifying women affects boys' general beliefs about sexual relationships and feminine sexual roles (Aubrey et al., 2011; Fredrickson \& Roberts, 1997; 
Tolman, 2013). To date, no empirical study has investigated the theorized explanatory value of boys' objectification of women/girls in a model over time, with models instead focusing more often on girls (e.g., Aubrey, 2006; Vandenbosch \& Eggermont, 2012). We were able to test this model here.

With these goals in mind, we identified and tested the following hypotheses:

H1: Consumption of sexualizing magazines predicts stronger endorsement of gender-stereotypical beliefs about courtship one year later.

H2. A test of reciprocal relations: Holding gender-stereotypical beliefs about courtship strategies positively predicts consumption of sexualizing magazines one year later.

H3. Relations between sexualizing magazines and gender-stereotypical beliefs about courtship strategies are mediated by the objectification of women.

\section{Method}

\section{Sample and Participant Selection}

Between March 2010 and March 2011, a three-wave panel study with an interval of six months was conducted among 12- to 18-year-old boys from 12 schools in different regions of Belgium. Approval for the survey was granted by the institutional review board of the host university. Informed consent was obtained in accordance with customary guidelines in Belgium. Students were informed that the study investigated their leisure habits. The study was part of a project that also aimed to study girls; overall, $93.4 \%$ of the sample targeted at wave 1 completed surveys at wave $1(N=1504)$. More precisely, every boy present during school visits at Waves $1(N$ =911), $2(N=841)$, and $3(N=860)$ completed paper surveys; 592 male students completed the three questionnaires $(65 \%)$. The mean age was $15.19(S D=1.41)$; the age distribution at Wave 1 was 12 (0.7\%), $13(13.7 \%), 14(21.6 \%), 15(16.3 \%), 16(29.6 \%), 17(15.4 \%)$ and $18(2.7 \%)$. A majority of the sample (93.7\%) was born in Belgium, and $49.8 \%$ followed a general educational program, which is representative of the overall Belgian school population (Department of Education, 2011). 
A $\chi^{2}$-test revealed that subjects who participated in one wave $(N=318 ; 35.5 \%)$ were significantly less likely to be enrolled in a general educational program than those who completed all three waves $(N=592 ; 49.8 \%), \chi^{2}(3)=80.35, p<.001$. A MANOVA analysis using Pillai's Trace, $V$ $=.01, F(4,827)=1.93, p>.05, \eta p^{2}=.01$ showed no significant differences between teens who participated in one wave and those who participated in all waves for age, use of sexualizing magazines, objectification of women, and courtship beliefs. Also, Little's Chi-Square Test of MCAR showed in each wave $(p>.05)$ that the data of the key variables (i.e., use of sexualizing magazines, objectification of women, and courtship beliefs) were missing completely at random $(N=592)$.

\section{Measures}

Pubertal status. In line with prior research (McCabe, Ricciardelli, \& Finemore, 2002), two items from the Pubertal Development Scale were included (Petersen, Crockett, Richards, \& Boxer, 1988): "Describe the level of body hair growth" and "Describe the development of voice change" $(r$ $=.56, p<.001)$. Respondents answered these items with not yet started (1), just started (2), is still going on (3), seems complete (4) or I don't know (coded as missing).

Exposure to sexualizing magazines. Using a 5-point scale anchored by (almost) never at 1 and (almost) every week at 5, participants indicated how often they read men's magazines such as $P$ magazine (a local version of Maxim), erotic magazines, such as Playboy, and pornographic magazines, such as Super 2000. To attribute more weight to magazine categories perceived as more sexualizing, college students (9 males and 20 females) were trained to assess the level of sexualization in media content, which was described as a visual and thematic focus on the body and appearance in a sexualized manner (APA, 2007; Aubrey, 2006). After the training, the college students answered three questions on a 5-point scale for each magazine type, drawing on the approach of Zurbriggen et al. (2011). The questions focused on the frequency and intensity of sexualization and their familiarity with the magazine type (Please see Zurbriggen et al. (2011), and Vandenbosch and Eggermont (2013), for a full description of the procedure). Resulting from this 
procedure was a sexualization score for men's magazines $=0.72$, erotic magazines $=0.81$, and pornographic magazines $=0.84$. These ratings were used to weight adolescents' magazine reading responses by multiplying the frequency rating of consuming a particular magazine genre by the sexualization score for that genre. A principal components analysis (PCA) indicated that each of the three sexualizing magazine categories for Wave 1 loaded on a single factor with a value above .40 (Eigenvalue: 1.85 ; Explained variance: $61.77 \% ; \alpha=.68)$. Similar results were found for Waves $2(\alpha$ $=.75)$ and $3(\alpha=.78)$.

Objectification of women. Respondents evaluated how important they considered four body attributes for girls and women in general on a 10-point scale, ranging from not at all important $(=1)$ to very important $(=10)$. This scale, which was inclusive of both women and girls, built on similar measures assessing men's views of women (e.g., Swami et al., 2010; Ward, Hansbrough, \& Walker, 2005). Because research indicates that especially women's buttock, breasts, belly, and body size are sexualized (APA, 2007; Fredrickson \& Roberts, 1997), we selected those body attributes. PCA showed that every body attribute loaded on a single factor with a value above .40 (Eigenvalue: 2.50 ; Explained variance: $62.60 \% ; \alpha=.80)$. Similar results emerged for Waves $2(\alpha=.84)$ and $3(\alpha=.88)$. An average score on the importance attributed to the four female body attributes was calculated.

Beliefs about feminine courtship strategies (BFCS). A scale was developed based on literature on gender-stereotypical beliefs (e.g., Tolman, Kim, Schooler, \& Sorsoli, 2007), on three scales assessing gendered sexual attitudes (Murnen \& Byrne, 1991; Snell, 1998; Ward, 2002), and on a pilot study of 56 adolescents. This pilot study involved 17 focus group discussions examining adolescents' experiences with sexual media effects, and, in particular, the types of beliefs that media promote regarding courtship strategies in heterosexual relationships. Based on the pilot study, a nineitem scale was developed tapping gender-stereotypical beliefs about feminine courtship strategies (BFCS) in heterosexual relationships (See Table 1). Moreover, the focus group interviews ensured that items from existing English scales were applicable to Flemish adolescents. 
Respondents evaluated the nine statements using a 5-point scale ranging from I totally disagree (1) to I totally agree (5). PCA showed that each statement loaded on a single factor with a value above .40 (Eigenvalue: 2.95; Explained variance: $32.74 \% ; \alpha=.74$ ). Similar results emerged for Waves $2(\alpha=.76)$ and $3(\alpha=.79)$. Moreover, a confirmatory factor analysis further confirmed in each wave that the data fit the hypothesized measurement model, RMSEA $=.05-.08$, AGFI $=.94-$ $.96, \chi^{2} / \mathrm{df}=2.33-3.63$. An average score was calculated representing respondents' level of genderstereotypical beliefs about feminine courtship strategies.

\section{Results}

\section{Descriptive Statistics and Preliminary Analyses}

Descriptive statistics are presented in Table 1. On average, boys occasionally read men's magazines (unweighted $M=1.62, S D=1.01)$, erotic magazines $(M=1.33, S D=.75)$, and pornographic magazines $(M=1.15, S D=.58)$. Furthermore, boys highly valued the sexualized body parts of women. Women's breasts and buttocks were considered as the most important body attributes, closely followed by body size and belly. In addition, gender-stereotypical BFCS were present among boys to a moderate degree.

Three repeated-measures analyses of variance tests were conducted to compare scores over time. No differences emerged for use of sexualizing magazines over time, $F(1.94,1114.09)=2.63, p$ $>$.05. Differences did, however, emerge for objectification of women, $F(1.96,1135.26)=23.03, p<$ .001 , and BFCS, $F(1.92,1110.35)=3.18, p<.05$. Pairwise comparisons demonstrated that respondents scored significantly higher on objectification of women at Wave $1(M=8.55 ; S D=$ 1.08) than at Wave $3(M=8.29 ; S D=1.24)$, and on BFCS at Wave $2(M=3.46 ; S D=.50)$ than at Wave $3(M=3.40 ; S D=.53)$. Regarding the latter, neither the score from Wave 2 or Wave 3 differed from the score of Wave $1(M=3.45)$.

Zero-order correlations are presented in Table 2. In line with the repeated-measures tests, most variables correlated negatively with age, suggesting a decrease in consumption of sexualizing 
magazines, acceptance of objectification of women, and BFCS with age. Furthermore, the longitudinal correlations provided some first evidence for both the reciprocal relation between sexualizing magazines and BFCS $(\mathrm{H} 1-\mathrm{H} 2)$, and the possible mediating role of the objectification of women in this association (H3).

\section{Testing Hypothesized Impact of Magazines on Courtship Strategies}

The hypotheses were further tested with structural equation modeling (AMOS), using the maximum likelihood method. The $\chi^{2} / \mathrm{df}$, the RMSEA, and the AGFI were used to address model fit (Byrne, 2010). Prior values of the respondents were entered as control variables. Consistent with previous sexual media research by Peter and Valkenburg (2007), the analyses tested first, the influence of sexualizing magazines on sexual beliefs, and, second, the potential mediating role of a third variable (i.e., objectification of women) in this sexual media-sexual beliefs relation.

Hypotheses 1 and 2. A first model (See figure 1) tested whether exposure to sexualizing magazines triggered feminine courtship beliefs over time, and vice versa. The model demonstrated an adequate fit of the data, $\chi^{2}(236)=507.45, p<.001, \mathrm{RMSEA}=.04, \mathrm{AGFI}=.91, \chi^{2} / d f=2.15$, and confirmed that more frequent exposure to sexualizing magazines (Wave 1) triggers beliefs about feminine courtship strategies (Wave 3 ) over time, $\beta=.10, B=.18, S E=.08, p<.05$. However, BFCS (Wave 1) did not significantly predict the use of sexualizing magazines (Wave 3) over time, $p$ $>.05$, suggesting the reciprocal relation is less likely than the media effects relation.

Hypothesis 3. Hypothesis 3 proposes a mediational model in which objectification of women mediates the relation between sexualizing magazines and BFCS. Baron and Kenny (1986) hypothesized that such models may occur under the following conditions. First, the independent variable (sexualizing magazines) significantly predicts the dependent variable (BFCS), when the mediator (objectification of women) is absent. This condition was met in the above-presented model. Second, the independent variable significantly predicts the proposed mediator. Third, the mediator significantly predicts the dependent variable. Finally, the relation between the independent and 
dependent variable should be weaker after adding the mediator into the model. The latter conditions were tested in a second, meditational model. Due to the complexity of this second model, item parceling was applied to scales with more than three items (i.e., objectification of women and BFCS). Item parcels are expected to enable the prediction of more stable parameters (Bandalos, 2002) and were constructed based on the rank order results of the factor loadings of each item (PCA).

The model demonstrated an adequate fit of the data, $\chi^{2}(281)=496.49, p<.001$, RMSEA $=$ $.04, \mathrm{AGFI}=.92, \chi^{2} / d f=1.77$, and supported the mediating role of objectification of women. In line with the second condition, use of sexualizing magazines (Wave 1) significantly predicted the objectification of women (Wave 2), $\beta=.11, B=.36, S E=.13, p<.005$. In turn, the objectification of women (Wave 2) significantly predicted BFCS (Wave 3), $\beta=.09, B=.05, S E=.02, p<.05$.

To address whether the relation between using sexualizing magazines (Wave 1) and BFCS (Wave 3) was fully mediated by objectification of women (time 2), a direct relation between sexualizing magazines (Wave 1) and BFCS (Wave 3) was added to the model, and the fit of this "extended" model was compared with the fit of the above reported model (see Figure 2). The results indicated that the extended model had a good fit of the data, $\chi^{2}(281)=494.37, p<.001$, RMSEA $=$ $.04, \mathrm{AGFI}=.92, \chi^{2} / d f=1.77$, but was not superior to the original fit. Moreover, the direct relation was not significant $(p>.05)$. The latter results thus confirm the third principle of mediation.

In addition, we calculated the indirect effect of sexualizing magazines on BFCS through objectification of women by multiplying the indirect standardized path coefficients (Cohen \& Cohen, 1983). To test whether the indirect effect was different from zero, we applied a bootstrapping method and used multiple imputation to account for missing values (Honaker \& King, 2010). A total of 1,000 bootstrap samples were generated from the dataset, and a $90 \%$ confidence interval (CI) was calculated. A mediation test revealed that when boys read sexualizing magazines more frequently (Wave 1), their objectification of women increased (Wave 2), and this result was, in turn, related to higher gender-stereotypical BFCS (Wave 3) $(.01=.11$ x.09; CI $=.000-.053)$. 
The model reported in Figure 2 thus confirmed hypothesis 3. However, this fully nested model also showed that sexualizing magazines (Wave 2) no longer predicted objectification of women (Wave 3), suggesting these media may only influence a limited amount of variance of boys' objectification of women.

\section{Post-Hoc Analyses Concerning Age and Pubertal Status}

Based on prior research (e.g., Eggermont, 2005; Vandenbosch \& Eggermont, 2013), we tested whether the above-presented models (Figures 1 and 2) were moderated by age as a categorical variable: $12-15$ year olds $(52.3 \% ; N=295)$ vs. $16-18$ year olds $(47.7 \% ; N=296)$. We also tested whether the above-presented models were moderated by pubertal status. Pubertal status was recoded into a new dichotomous variable: adolescents in an early pubertal stage (0), included adolescents whose pubertal development had not yet started, had just started, or was still going on $(67.3 \% ; N=$ 342), and adolescents in an advanced pubertal stage (1) included adolescents whose pubertal development seemed complete for at least one of the two items $(32 \% ; N=166)$. No significant moderation effects of age or pubertal status on the hypothesized relations were found.

\section{Discussion}

Initiating romantic relationships can be a challenging task for many adolescent boys (Shulman et al., 2011; Tolman et al., 2004), leading some to seek guidance on how to court girls from the models around them (e.g., friends, siblings). Because the media offer abundant examples of successful courtship, some boys may rely on these models, as well, either consciously or inadvertently. However, the "information" provided by the media is skewed, emphasizing a girl's sexual body parts (i.e., breasts and buttocks) as central to her worth over other attributes, such as her kindness, ambition, intelligence, or wit. We therefore explored how exposure to sexualizing magazines affects adolescent boys' beliefs about women and courtship. The results of our three-wave panel study provide some of the first longitudinal evidence that sexualizing magazines may influence boys' developing courtship cognitions. We found that the more boys consume sexualizing 
magazines, the more importance they assign to girls' body size and sexual body parts. In turn, this objectification of girls was found to trigger acceptance of courtship strategies that center on appearance. We anticipate that adopting these perspectives of women and courtship is likely to affect boys' developing heterosexual relations in multiple ways; we outline three below.

One potential consequence concerns the interpretation of sexual signals. Because adolescent boys are newly discovering the "other" sex, they are likely to be uncertain about what girls in a romantic context mean when they act in a particular way (Giordano, Longmore, \& Manning, 2006; Smiler, 2013). Boys who strongly endorse stereotypical beliefs about courtship strategies may interpret girls who are attractive, dressed up, or wearing makeup as an invitation to flirt; they may thus perceive a girl's outward appearance as a flirtatious “cue.” For readers of sexualizing magazines, these misinterpretations may be even more likely because the content deemphasizes the complexity of the emotions and personalities associated with sexual attraction in favor of physical attributes (Bogaert et al. 1993; Ricardielli et al., 2010). As a result, readers are provided with limited examples of other, alternative cues to evaluate girls' intentions. These misinterpretations may result in unwanted sexual attention or sexual harassment (Abbey, 1982; Sigal et al., 1988).

A second consequence of accepting these objectifying views of courtship concerns unfavorable comparisons to real women (Kenrick \& Guttierres, 1980). When adolescent boys frequently read sexualizing magazines and internalize their courtship beliefs regarding appearance, they may only consider highly attractive girls as "appropriate dating material." This consideration may profoundly harm boys' and girls' well-being. When girls are only valued for their appearance, they may feel objectified, and their well-being may be negatively affected (APA, 2007). When boys only consider girls who match the appearance ideal as dating partners or fixate on their appearance, the likelihood of a successful long-term relationship is compromised. Although sexual attractiveness is important in a relationship, research indicates that dimensions related to a partner's personality become more important after the initial encounters (Buunk, Dijkstra, Fetchenhauer, \& Kenrick, 2002; 
Regan \& Berscheid, 1999). An exclusive focus on a girl's appearance may therefore decrease a boy's chance of sustaining a long-term romantic relationship. Indeed, Zurbriggen et al. (2011) reported that among young men, frequent consumption of sexually objectifying media (magazines, TV, films) was associated with greater objectification of one's romantic partner, which itself was linked with lower relationship satisfaction and sexual satisfaction. Together with our study results, these findings suggest that the objectification of the female body may inhibit boys from developing satisfying, intimate, relationships with actual women.

A third consequence concerns adolescent boys' comfort with their own bodies. Across several studies, findings indicate that exposure to sexually objectifying images of women is linked with young men's feeling more discomfort with their own bodies, as indicated by higher levels of self-objectification and body surveillance, and lower body esteem (Aubrey, 2006; Dens, DePelsmacker, \& Janssens, 2009; Johnson, McCreary, \& Mills, 2007). For example, Aubrey and Taylor (2009) reported that young men exposed to magazine images of sexualized women expressed more body self-consciousness, greater appearance anxiety, and less confidence in their own romantic abilities. Aubrey and Taylor argue that exposure to sexualized images of women in lad magazines seems to make men anxious about their own appearance, perhaps by priming concerns about whether they are attractive enough to successfully pursue women like those pictured.

In view of these negative implications, future research is needed to explore which factors may protect boys from such effects. For example, research may explore whether media literacy education concerning the objectification of women, which has been found to raise young women's awareness of this issue and increase their self-esteem (Choma, Foster, \& Radford, 2007), could prevent boys from adopting gender-stereotypical beliefs. In addition, other socialization agents, such as parents, have been identified as moderators of the association between media use and sexual attitudes (e.g., Ashby, Arcari, \& Edmonson, 2006), and may also function as a buffer against the impact of sexualizing magazines. Future analyses may want to interview boys and young men who 
are aware of these scripts, but who actively reject them (Epstein, Calzo, Smiler, \& Ward, 2009; Smiler, 2013). What factors might predict this resistance? Future research might also explore the moderating role of culture. This study demonstrates that the Heterosexual Script, which was initially developed to study patterns in North America (Kim et al., 2007), is also relevant in a Western European context. Nevertheless, the reported relations were relatively small, with correlations ranging from .10 to .18 . Future research could test potential differences in the magnitude of sexual media effects reported in North American and Western European samples.

At the same time, the possibility of a reciprocal relation between sexualizing magazines and BFCS was not supported. We found no evidence that adolescent boys' consumption of men's magazines is driven by their existing sexual beliefs. It is possible that evidence of a media selection process may be stronger when moderating factors are considered, such as race, religion, and relationship status (Ward, 2003). Future research should explore the possible value of such moderators for adolescents' selection of sexualizing media content.

Explanatory mechanism of the objectification of women. Building on the combined theoretical frameworks of objectification theory (Fredrickson \& Roberts, 1997), the centerfold syndrome (Brooks, 1997), and the Heterosexual Script (Kim et al., 2007), the study also supported expectations that associations between sexualizing magazines (time 1) and BFCS (time 3) are mediated by boys' objectification of women (time 2). This finding highlights the value of organizing and integrating assumptions of closely-related theoretical perspectives, and also highlights the role of objectification as a mediator. Future research may explore whether the objectification of women also explains other associations between sexualizing media and men's sexual beliefs, such as their acceptance of sexual aggression (Aubrey et al., 2011; Taylor, 2006; Vega \& Malamuth, 2007).

However, our data also suggest that the effects of sexualizing magazines on boys' objectification of women are limited, as we found that sexualizing magazines at time 1 predicted the objectification of women at time 2 , but did not find that sexualizing magazines at time 2 affected the 
objectification of women at time 3. It is possible that media may only influence objectifying beliefs about women up to a certain extent, and that effects may get diluted over time by other forces in boys' environments, especially if the messages from these sources are consistent with media input. The intersecting contributions of media with other forces should be examined in future research.

Limitations. Although our findings make unique contributions concerning the impact of sexualizing media, we acknowledge several limitations that future studies will want to address. First, the Western European study context limits generalizability of the findings to other cultures, especially non-Western ones. Nevertheless, the findings do offer some insight into how sexualizing media may impact European adolescents and supports the suggestion in prior research that effects of sexualizing media are similar across Western cultures (APA, 2007; Moradi \& Huang, 2008). Second, the study introduced a new measure on the objectification of women, but acknowledges and strongly supports the need for further research to validate this measure. There are no standardized measures that examine men's sexual objectification of women, for most measures focus on self-objectification. This future research might also explore whether boys respond differently to questions on the body parts of women versus questions on the body parts of girls. Third, this study focused solely on magazines and not other media formats, such as movies or Internet pornography. Future research may want to compare contributions across media, and test whether "still" sexualized images are equally impactful as moving images. Finally, although no significant differences emerged between adolescents participating in all waves and those who dropped out of the study, we cannot rule out that differences may have existed on factors not measured here.

Conclusion. Our findings highlight the need for more research on the effects of sexualizing media on adolescent boys. We found that frequent users of sexualizing magazines were more likely to endorse gender-stereotypical courtship strategies, but found no evidence for a reciprocal relation. Our study also supports the mediating role of objectification of women in an explanatory model for sexual media effects among boys, and highlights the need for more research on its role. 


\section{References}

Abbey, A. (1982). Sex differences in attributions for friendly behavior: Do males misperceive females' friendliness? Journal of Personality and Social Psychology, 42, 830-838. doi:10.1037/0022-3514.42.5.830

APA, Task Force on the Sexualization of Girls. (2007). Report of the APA Task Force on the Sexualization of Girls. Retrieved from http://www.apa.org/pi/wpo/sexualization.html

Ashby, S. L., Arcari, C. M., \& Edmonson, M. B. (2006). Television viewing and risk of sexual initiation by young adolescents. Archives Pediatrics Adolescence Medics, 160, 375-380. doi: 10.1001/archpedi.160.4.375

Aubrey, J. S. (2006). Exposure to sexually objectifying media and body self-perceptions among college women: An examination of the selective exposure hypothesis and the role of moderating variables. Sex Roles, 55, 159-172. doi:10.1007/s11199-006-9070-7

Aubrey, J. (2007). Does television exposure influence college-aged women's sexual self-concept? Media Psychology, 10, 157-181. doi: 10.1080/15213260701375561

Aubrey, J. S., Hopper, K. M. \& Mbure, W.G. (2011). Check that body! The effects of sexually objectifying music videos on college men's sexual beliefs. Journal of Broadcasting \& Electronic Media, 55, 360-379. doi:10.1080/08838151.2011.597469

Aubrey, J. S., \& Taylor, L. D. (2009). The role of lad magazines in priming men's chronic and temporary appearance-related schemata: An investigation of longitudinal and experimental findings. Human Communication Research, 35, 28-58.

Baker, C. (2005). Images of women's sexuality in advertisements: A content analysis of Black- and White-oriented women's and men's magazines. Sex Roles, 52, 13-27.

Bandalos, D. L. (2002). The effects of item parceling on goodness-of-fit and parameter estimate bias in structural equation modeling. Structural Equation Modeling, 9 (1), 78-102. doi:10.1207/S15328007SEM0901_5 
Baron R. M., \& Kenny D. A. (1986). The moderator-mediator variable distinction in social psychological research: Conceptual, strategic, and statistical considerations. Journal of Personality and Social Psychology,51, 1173-1182. doi:10.1037/0022-3514.51.6.1173.

Bleakly, A., Hennessy, M., \& Fishbein, M. (2011). A model of adolescents's seeking of sexual content in their media choices. Journal of Sex Research, 48 (4), 309-315. doi:10.1080/00224499.2010.497985

Bleakly, A., Hennessy, M., Fishbein, M., \& Jordan, A. (2008). It works both ways: The relationship between exposure to sexual content in the media and adolescent sexual behavior. Media Psychology, 11, 443-46. doi:10.1080/15213260802491986

Bogaert, A. F., Turkovich, D. A., \& Hafer, C. L. (1993). A content analysis of playboy centerfolds from 1953 through 1990: Changes in explicitness, objectification, and model's age. Journal of Sex Research, 30, 135-139. doi:10.1080/00224499309551693

Brooks, G. R. (1997). The Centerfold Syndrome. Signs of Life in the USA: Readings on Popular Culture for Writers. Boston: Bedford Books.

Buunk, B. P., Dijkstra, P., Fetchenhauer, D., \& Kenrick, D. (2002). Age and gender differences in mate selection criteria for various involvement levels. Personal Relationships, 9, 271-278. doi: $10.1111 / 1475-6811.00018$

Byrne, B. M. (2010). Structural equation modeling with AMOS: Basic concepts, applications and programming. Mahwah, NJ: Lawrence Erlbaum Associates.

Choma B. L., Foster M. D., \& Radford, E. (2007). Use of objectification theory to examine the effects of a media literacy intervention on women. Sex Roles, 56, 581-591. doi. $10.1007 / \mathrm{s} 11199-007-9200-\mathrm{x}$

Cohen, J., \& Cohen, P. (1983). Applied multiple regression/correlation analysis for the behavioral sciences (2nd ed.). Hillsdale, NJ: Lawrence Erlbaum Associates. 
Dens, N., de Pelsmacker, P., \& Janssens, W. (2009). Effects of scarcely dressed models in advertising on body esteem for Belgian men and women. Sex Roles, 60, 366-378.

Department of Education (2011). Statistisch jaarboek van het Vlaams Onderwijs, schooljaar 2010_2011. Belgium: Brussels [Statistical yearbook of Flemish Education, academic year 2010_2011].

Eggermont, S. (2005). Young adolescents perception of peer sexual behaviors: the role of television viewing. Child Care, Health and Development, 41, 459-468.

Epstein, M., Calzo, J., Smiler, A., \& Ward, L. M. (2009). "Anything from making out to having sex": Men's negotiations of hooking up \& friends with benefits scripts. Journal of Sex Research, 46, 414-424.

Ezzell, M. B. (2009). Pornography, lad mags, video games, and boys: Reviving the canary in the cultural coal mine. In S. Olfman (Ed.) The sexualization of childhood (pp. 7-32). Westport, CT: Praeger Publishers/Greenwood Publishing Group.

Ferris, A. L., Smith, S., Greenberg, B. S., \& Smith, S. (2007). The content of reality dating shows and viewer perceptions of dating. Journal of Communication, 57, 490-510.

Festinger, L. (1957). Theory of Cognitive Dissonance. Stanford, CA: Stanford University Press. Frable, D., Johnson, A., \& Kellman, H. (1997). Seeing masculine men, sexy women, and gender differences: Exposure to pornography and cognitive constructions of gender. Journal of Personality, 65 (2), 311-355.

Fredrickson, B. L., \& Roberts, T. A. (1997). Objectification theory: Toward understanding women's lived experiences and mental health risks. Psychology of Women Quarterly, 21, 173-206. doi:10.1111/j.1471-6402.1997.tb00108.x

Giordano, P.C., Longmore, M.A., \& Manning, W.D. (2006). Gender and the meanings of adolescent romantic relationships: A focus on boys. American Sociological Review, 71, 260-287. 
Hargreaves, D., \& Tiggemann, M. (2003). Female “thin ideal” media images and boys' attitudes toward girls. Sex Roles, 49 (9-10), 539-544.

Hust, S., \& Lei, M. (2008). Sexual objectification, sports programming, and music television. Media Report to Women, 36 (1), 16-23.

Honaker J., \& King G. (2010). What to do about missing values in time series cross-section data. American Journal of Political Science, 54, 561-81. doi: 10.1111/j.1540-5907.2010.00447.x

Johnson, P., McCreary, D., \& Mills, J. (2007). Effects of exposure to objectified male and female media images on men's psychological well-being. Psychology of Men \& Masculinity, 8 (2), 95-102.

Kenrick, D. T., \& Gutierres, S. E. (1980). Contrast effects and judgments of physical attractiveness: When beauty becomes a social problem. Journal of Personality and Social Psychology, 38, 131-140. doi: 10.1037/0022-3514.38.1.131

Kenrick, D. T, Gutierres, S. E., \& Goldberg, L. (1989). Influence of popular erotica on judgments of strangers and mates. Journal of Experimental Social Psychology, 38, 131-140. doi: 10.1016/0022-1031(89)90010-3

Kim, J. L., Sorsoli, L., Colins, K., Zylbergols, B. A., Schooler, D., \& Tolman, D. L. (2007). From sex to sexuality: Exposing the heterosexual script on primetime network television. Journal of Sex Research, 44, 145-157. doi: 10.1080/00224490701263660

Kistler, M. E., \& Lee, M. J. (2010). Does exposure to sexual hip-hop music videos influence the sexual attitudes of college students? Mass Communication and Society, 13, 67-86.

Krassas, N.R., Blauwkamp, J. M., \& Wesselink, P. (2001). Boxing Helena and corseting Eunice: Sexual rhetoric in Cosmopolitan and Playboy magazine. Sex Roles, 44, 1-21.

Krassas, N.R., Blauwkamp, J. M., \& Wesselink, P. (2003). "Master your Johnson”: Sexual rhetoric in Maxim and Stuff magazines. Sexuality \& Culture, 7, 98-119. 
McCabe, M., Ricciardelli, L., \& Finemore, J. (2002). The role of puberty, media, and popularity with peers on strategies to increase weight, decrease weight, and increase muscle tone among adolescent boys and girls. Journal of Psychosomatic Research, 52 (3), 145-154.

Moradi, B., \& Huang, Y. (2008). Objectification theory and psychology of women: A decade of advances and future directions. Psychology of Women Quarterly, 32, 377-398. doi:10.1111/j.1471-6402.2008.00452.x

Murnen, S., \& Byrne, D. (1991). Hyperfemininity: Measurement and validation of the construct. Journal of Sex Research, 28 (3), 479-489.

Pardun, C. J., L’Engle, K. L., \& Brown, J. D. (2005). Linking exposure to outcomes: Early adolescents' consumption of sexual content in six media. Mass Communication \& Society, 8 , 75-91.

Peter, J., \& Valkenburg, P. (2007). Adolescents' exposure to a sexualized media environment and their notions of women as sex objects. Sex Roles, 56, 381-395.

Petersen, A., Crockett, L., Richards, M., \& Boxer, A. (1988). A self-report measure of pubertal status: Reliability, validity, and initial norms. Journal of Youth and Adolescence, 17 (2), 117-133.

Regan, P. C., \& Berscheid, E. (1999). Lust: What we know about a man's sexual desire. Thousand Oaks, C A: Sage.

Ricciardelli, R., Clow, K., \& White, P. (2010). Investigating hegemonic masculinity: Portrayals of masculinity in men's lifestyle magazines. Sex Roles, 63 (1-2), 64-78. Doi: 10.1007/s11199010-9764-8

Rideout, V., Foehr, U., \& Roberts, D. (2010). Generation $M^{2}$ : Media in the lives of 8-to 18-yearolds. Menlo Park, CA: The Henry J. Kaiser Family Foundation. 
Sanchez, T. Fetterolf, J. C. \& Rudman, L. A. (2012). Eroticizing inequality in the United States: The consequences and determinants of traditional gender role adherence in intimate relationships. Journal of Sex Research, 2-3, 168-183. doi:10.1080/00224499.2011.653699

Shulman, S., Connolly, J., \& McIsaac, C. J. (2011). Romantic relationships. In B. Bradford Brown and Mitchell J. Prinstein (Eds.), Encyclopedia of Adolescence, Volume 2 (pp. 289-297).

London: Elsevier, Inc., Academic Press.

Sigal, J., Gibbs, M., Adams, B., \& Derfler, R. (1988). The effect of romantic and non-romantic films on perception of female friendly and seductive behavior. Sex Roles, 19, 545-554. doi:10.1007/BF00289734

Smiler, A. P. (2013). Challenging Casanova: Beyond the stereotype of the promiscuous young male. San Francisco, CA: Jossey Bass.

Snell, W. E., Jr. (1998). The Stereotypes about Male Sexuality Scale. In C.M. Davis, W.L. Yarber, R. Baurerman, G. Schreer, \& S.L. Davis (Eds.), Handbook of sexuality-related measures: A compendium ( $\left.2^{\text {nd }} e d.\right)$ (pp. 463-465). Thousand Oaks, CA: Sage.

Stankiewicz, J. M., \& Rosselli, F. (2008). Women as sex objects and victims in print advertisements. Sex Roles, 57, 579-589. doi:10.1007/s11199-007-9359-1

Swami, V., Coles, R., Wilson, E., Salem, N., Wyrozumska, K., \& Furnham, A. (2010). Oppressive beliefs at play: Associations among beauty ideals and practices and individual differences in sexism, objectification of others, and media exposure. Psychology of Women Quarterly, 34, 365-379. doi: 10.1111/j.1471-6402.2010.01582.x

Taylor, L. D. (2006). College men, their magazines, and sex. Sex Roles, 55,693-702. doi: 10.1007/s11199-006-9124-X

Tolman, D. L. (2002). Dilemmas of desire: Teenaged girls talk about sexuality. Cambridge, MA: Harvard University Press. 
Tolman, D. (2013). It's bad for us too: How the sexualization of girls impacts the sexuality of boys, men, and women. In E. Zurbriggen and T. Roberts (Eds.), The sexualization of girls and girlhood: Causes, consequences, and resistance (pp. 84-106). New York: Oxford University Press.

Tolman, D. L., Kim, J. L., Schooler, D., \& Sorsoli, C. L., (2007). Rethinking the associations between television viewing and adolescent sexuality development: Bringing gender into focus. Journal of Adolescent Health, 40, 84.e9-84.e16. doi: 10.1016/j.jadohealth.2006.08.002

Tolman, D., Spencer, R., Harmon, T., Rosen-Reynoso, M., \& Striepe, M. (2004). Getting close, staying cool: Early adolescent boys' experiences with romantic relationships. In N. Way and J. Chu (Eds.), Adolescent boys: Exploring diverse cultures of boyhood (pp. 235-255). New York: New York University Press.

Valkenburg, P., \& Peter, J. (2013). The different susceptibility to media effects model. Journal of Communication, 63, 221-243.

Vandenbosch, L., \& Eggermont, S. (2012). Understanding sexual objectification: A comprehensive approach toward media exposure and girl's internalization of beauty ideals, selfobjectification and body surveillance. Journal of Communication, 62, 869-887. doi:10.1111/j.1460-2466.2012.01667.x

Vandenbosch, L., \& Eggermont, S. (2013). Sexually explicit websites and sexual initiation: Reciprocal relationships and the moderating role of pubertal status. Journal of Research on Adolescence, 23, 621-634. doi: 10.1111/jora.12008

Vega, V., \& Malamuth, N. M. (2007). Predicting sexual aggression: The role of pornography in the context of general and specific risk factors. Aggressive Behaviour, 33, 104-117. doi: 10.1002/ab.20172 
Ward, L. M. (2002). Does television exposure affect emerging adults' attitudes and assumptions about sexual relationships? Correlational and experimental confirmation. Journal of Youth and Adolescence, 31, 1-15.

Ward, L. M. (2003). Understanding the role of entertainment media in the sexual socialization of American youth: A review of empirical research. Developmental Review, 23, 347-388. doi:10.1016/S0273-2297(03)00013-3

Ward, L.M., Epstein, M., Caruthers, A., \& Merriwether, A. (2011). Men's media use, sexual cognitions, and sexual risk behavior: Testing a meditational model. Developmental Psychology, 47, 592-602. doi: 10.1037/a0022669

Ward, L. M., Hansbrough, E., \& Walker, E. (2005). Contributions of music video exposure to black adolescents' gender and sexual schemas. Journal of Adolescent Research, 20, 143-166. doi: $10.1177 / 0743558404271135$

Zillman, D., \& Bryant, J. (1985). Selective exposure to communication. Mahwah, NJ: Lawrence Erlbaum Associates.

Zurbriggen, E.L., \& Morgan, E.M. (2006). Who wants to marry a millionaire? Reality dating television programs, attitudes towards sex, and sexual behaviors. Sex Roles, 54, 1-17.

Zurbriggen, E. L., Ramsey, L.R., \& Jaworski, B. K. (2011). Self- and partner-objectification in romantic relationships: Associations with media consumption and relationship satisfaction. Sex Roles, 64, 449-462. doi: 10.1007/S11199-011-9933-4 
Table 1

Means and Standard Deviations for the Studied Variables

\begin{tabular}{|c|c|c|c|c|}
\hline & Min & $\operatorname{Max}$ & $M$ & $S D$ \\
\hline Sexualizing magazines W1 & .76 & 3.94 & 1.07 & .49 \\
\hline 1. Sexualizing pornographic magazines & .84 & 4.20 & .97 & .48 \\
\hline 2. Sexualizing erotic magazines & .81 & 4.03 & 1.07 & .61 \\
\hline 3. Sexualizing men's magazines & .72 & 3.60 & 1.16 & .73 \\
\hline Sexualizing magazines W2 & .72 & 3.94 & 1.12 & .54 \\
\hline Sexualizing magazines W3 & .76 & 4.12 & 1.10 & .55 \\
\hline Objectification of women W1 & 1 & 10 & 8.55 & 1.08 \\
\hline 1. Buttock & 1 & 10 & 8.61 & 1.30 \\
\hline 2. Belly & 1 & 10 & 8.42 & 1.36 \\
\hline 3. Breasts & 1 & 10 & 8.61 & 1.29 \\
\hline 4. Body size & 1 & 10 & 8.56 & 1.57 \\
\hline Objectification of women W2 & 1 & 10 & 8.57 & 1.03 \\
\hline Objectification of women W3 & 1 & 10 & 8.29 & 1.24 \\
\hline Beliefs about Feminine Courtship Strategies (BFCS) W1 & 1 & 5 & 3.45 & .50 \\
\hline 1. A handsome girl can get every boy she wants & 1 & 5 & 3.30 & 1.02 \\
\hline 2. Girls like to flirt with boys & 1 & 5 & 3.54 & .76 \\
\hline $\begin{array}{l}\text { 3. If a girl wishes to attract a boyfriend, she is advised to use her } \\
\text { appearance or body. }\end{array}$ & 1 & 5 & 3.65 & .88 \\
\hline $\begin{array}{l}\text { 4. If a girl wants to be attractive for her boyfriend, she is advised to work } \\
\text { on her body/appearance }\end{array}$ & 1 & 5 & 3.65 & .77 \\
\hline 5. Girls are expected to invest more in their appearance than boys. & 1 & 5 & 3.59 & .93 \\
\hline $\begin{array}{l}\text { 6. Girls with a well-shaped bust have an increased chance to successfully } \\
\text { seduce a boy }\end{array}$ & 1 & 5 & 3.31 & .98 \\
\hline 7. Girls only want real muscular guys & 1 & 5 & 3.45 & .78 \\
\hline 8. Girls like it when boys whistle at them & 1 & 5 & 3.37 & .84 \\
\hline 9. Girls often say "no" but really mean "yes" & 1 & 5 & 3.22 & .90 \\
\hline BFCS W2 & 1 & 5 & 3.46 & .50 \\
\hline BFCS W3 & 1 & 5 & 3.40 & .53 \\
\hline
\end{tabular}


Table 2

Zero-Order-Correlations between Age, Pubertal Status, Sexualizing Magazines, Objectification of Women, and BFCS

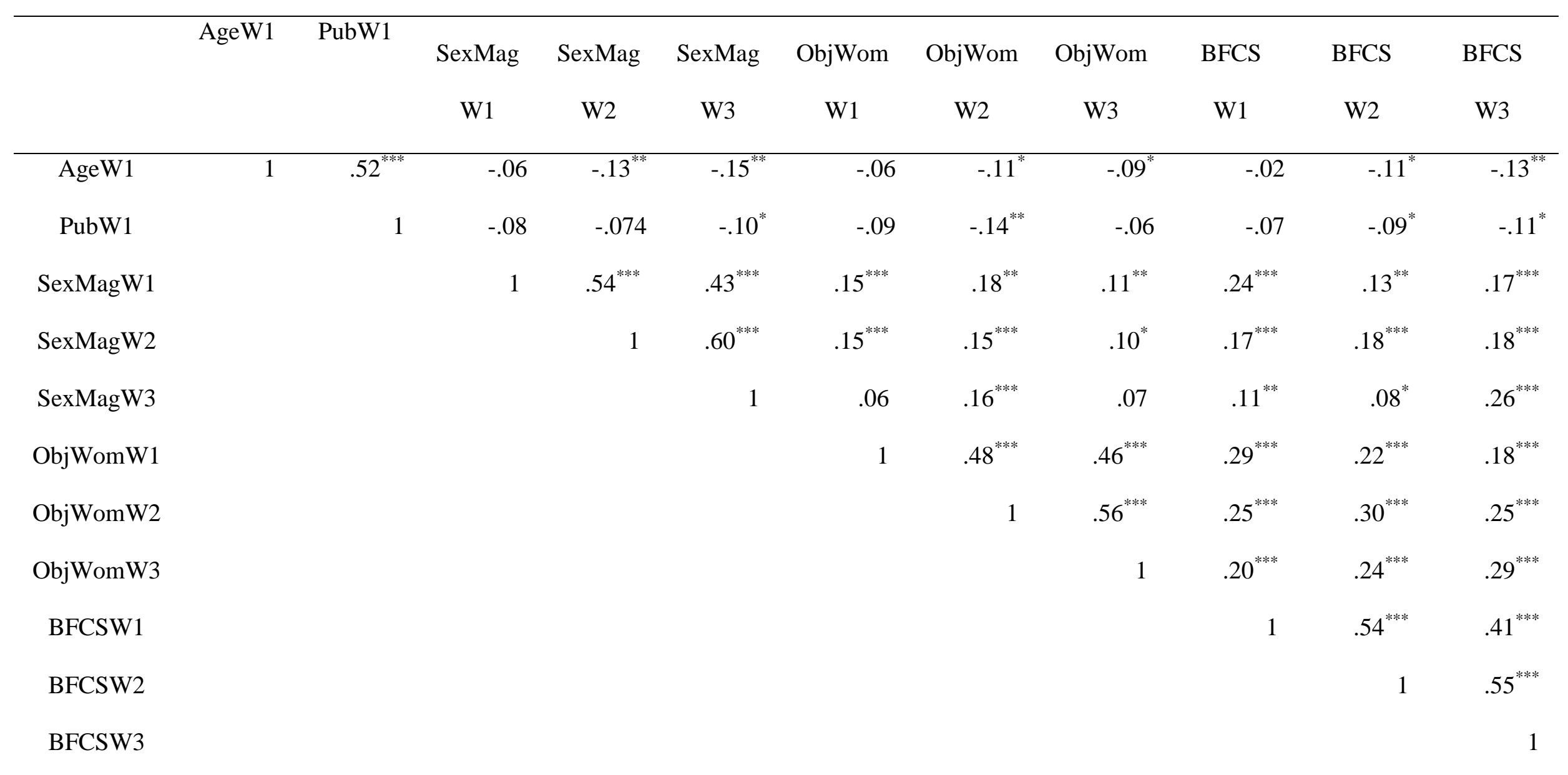

Note. ${ }^{*} p<.05 ; * *<.01 ; * * p<.001 ;$ Pub = Pubertal status, SexMag= Sexualizing magazines, ObjWom= Objectification of women, BFCS= Beliefs about feminine courtship strategies 


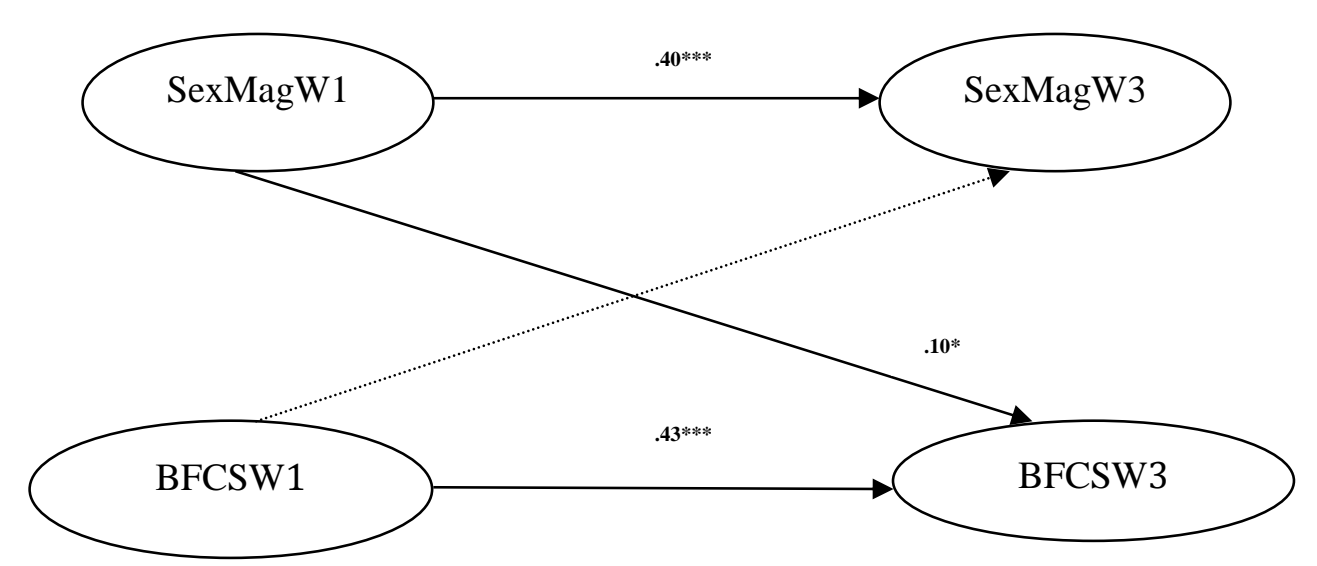

Figure 1. Structural equation model for the hypothesized relationships between sexualizing magazines and gender-stereotypical beliefs about feminine courtship strategies (BFCS). Note: $* p<.05 ; * * p<.01 ; * * p<.001$; For clarity, error terms, covariances, and measurements are not shown.

Dotted line indicates a non-significant pathway. 


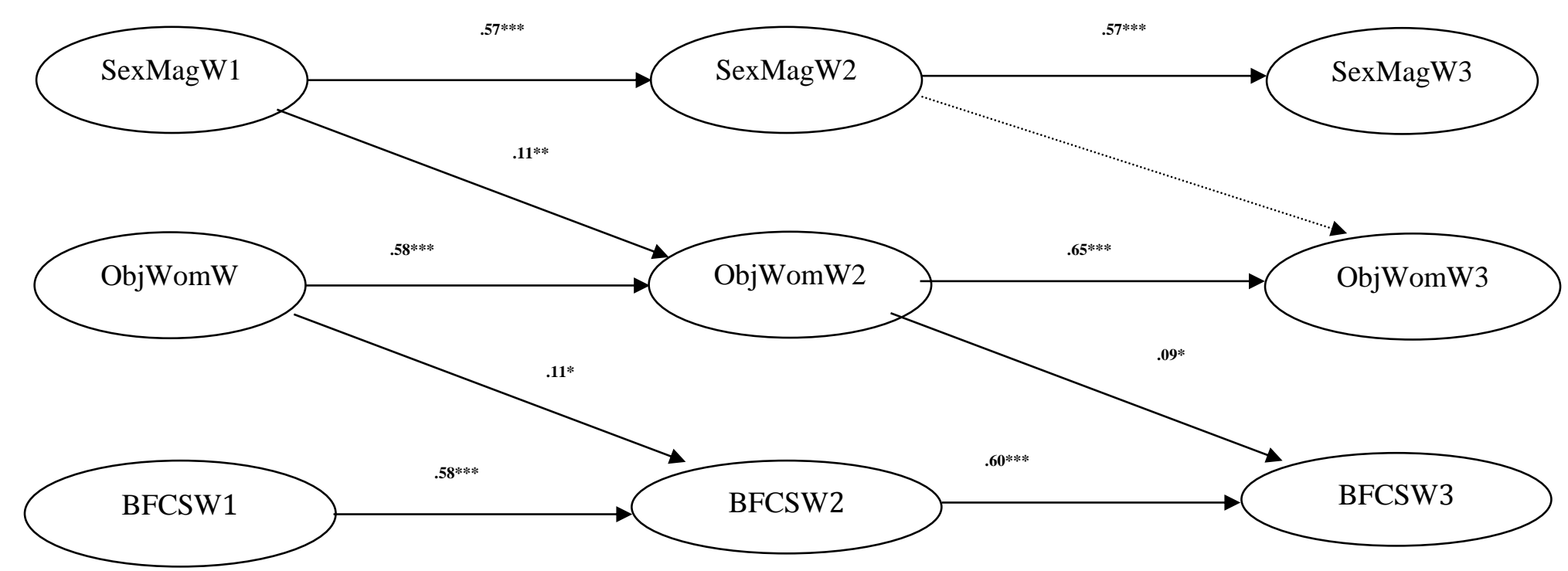

Figure 2. Structural equation model for the hypothesized relationships between sexualizing magazines, objectification of women, and BFCS. Note: ${ }^{*} p$ $<.05 ; * p<.01 ; * * p<.001$; SexMag = Sexualizing magazines, BFCS = Beliefs about feminine courtship strategies, ObjWom = Objectification of women; For clarity, error terms, covariances, and measurements are not shown. Dotted line indicates a non-significant pathway. 